\title{
Research on the construction mechanism of science and innovation corridor from the perspective of innovation chain
}

\author{
Li Jinghua $^{1}$, Han Ying ${ }^{1, *}$, and Liu Shulong ${ }^{1}$ \\ ${ }^{1}$ School of Business Administration, Zhejiang Gongshang University, Hangzhou, Zhejiang, China
}

\begin{abstract}
Based on the perspective of innovation chain, this paper takes Highway 128 and Guang-Shen Science and Technology Innovation Corridor as examples to explore the construction mechanism of science and technology innovation corridor. The findings are as follows: First, the corridor can be regarded as a virtual organization containing core nodes and auxiliary nodes. All nodes are not equal, and the core node plays the core function. Second, if the function of the core node is weakened, the science and innovation corridor will show a deterioration trend. Third, the construction of the science and innovation corridor is a process of the whole science and innovation chain from the flow and integration of knowledge resources, to the overflow of innovation incubation, and then to the market application. However, there are still problems in the chain, such as resource flow obstacles, innovation incubation breaks and structural imbalance. Therefore, in order to realize the benign interaction of multiple subjects in the science and innovation corridor, there needs to be a core subject that plays the role of agglomeration and diffusion, so as to realize the coordinated development of the corridor.
\end{abstract}

\section{Introduction}

The science and technology innovation corridor is a unique and efficient "organization" or innovation system. The science and innovation corridor has increasingly become an important way to promote regional innovation linkage. In the final analysis, the science and innovation corridor is a form of cross-regional organization, and how to build the corridor has become the focus of research.

This paper studies the sci-tech innovation corridor with the characteristics of cross-regional collaborative development. There are multiple subjects in the corridor that play the corresponding functions, and there must be a core subject that plays the core role. All subjects in the corridor should be in their respective positions and perform their respective functions, which is the necessary condition for the effective operation of the entire sci-tech innovation corridor. Since Schumpeter put forward the concept and theory of innovation, most scholars believe that innovation is not only the development of new scientific knowledge and technology, but also the transformation of these knowledge and technology into productive forces, and the industrialization of diffusion process. Around such understanding, science and innovation corridor from the beginning of the scientific knowledge source, containing a variety of main body, through multiple links, finally realizes the whole process of industrialization, a process that includes the government, colleges and universities, enterprises, financial institutions, research institutions, intermediary service agencies, and other innovative main body, the colleges and universities, enterprises and research institutes is an important function of innovation chain nodes, government departments, financial institutions, service organizations is the main point of science and technology innovation chain [1]. Among them, the innovation chain is an important component of the innovation ecosystem [2], and the structural imbalance in the innovation chain is the root of the problems such as "insufficient transformation of scientific and technological achievements" and "two layers of science and technology economy" that have always existed in China's economic development. Therefore, in combination with the actual situation of the collaborative innovation of the science and innovation corridor, the construction mechanism of Highway 128 and the Guang-Shenzhen Science and Technology Innovation Corridor is explored from the perspective of the innovation chain, so as to form a replicable, extensible construction mode [3], promote the in-depth development of the science and technology innovation corridor, and strengthen the overall science and technology innovation strength of the country. This study not only deepens the understanding of the science and innovation corridor, but also provides a reference for the construction of regional collaborative innovation of science and innovation corridor based on the innovation chain.

* Corresponding author: hanying9611@163.com 


\section{Analyze the construction mechanism of science and innovation corridor from the perspective of innovation chain}

The innovation chain is proposed from the thinking of the academic community on the innovation process. Most domestic and foreign scholars believe that the innovation chain is the whole process from front-end basic research and development to back-end industrialization diffusion, and the key of this process lies in the effective transformation of scientific and technological achievements [4]. Since Marshall \& Vredenburg put forward the concept of innovation chain, the earliest innovation chain was considered to be an interactive process among multiple subjects such as raw material suppliers, product manufacturers and product sellers [5]. Since then, domestic and foreign researchers have started to conduct a series of studies on the meaning, composition mode, tech-economic connection and functional nodes of the innovation chain [6]. In terms of connotation, the first category is defined from the perspective of process, emphasizing that the innovation chain is the whole process of innovation or transformation of scientific and technological achievements. The innovation chain is usually defined as the process from basic research to the formation of relevant scientific knowledge, which is used to create new technological products and finally the industrialization of the products [7]. Some scholars believe that innovation chain is a whole process in which multiple participants such as the government, enterprises, universities and research institutes rationally and optimally allocate resources and integrate with each other, and finally industrialize knowledge and technology achievements [8]. Another kind is based on the definition of the knowledge innovation Angle, thought innovation chain from scientific and technological knowledge to through technology innovation link to the process of industrialization, it around a core subject, on the basis of the market direction, through the knowledge innovation activities will be related to the innovation main body link, is a kind of is designed to process of knowledge economization and optimize the innovation system as the guidance function of chain structure model. It emphasizes that the innovation chain is the creation, transfer, dissemination and diffusion of knowledge. From this perspective, some scholars believe that the innovation chain is centered on one subject, which starts with innovative ideas, and then connects multiple complementary subject nodes to realize knowledge innovation and technological innovation through mutual integration and mutual division of labor. Some scholars also divide the innovation chain into two categories: horizontal chain and vertical chain. Horizontal chain refers to the process that takes product development as the core and realizes innovative design, research and development, industrialization and commercialization through the mutual integration of government, enterprises and scientific research institutions. Vertical chain refers to the chain structure formed around the connection between the upstream and downstream links of the industrial chain. Other scholars emphasize that innovation chain is a link between innovation subjects for the transfer and transformation of innovation elements, and the goal of producing innovative achievements is to meet the market demand [9]. The above scholars mainly studied the concept of innovation chain from two perspectives: one is that innovation chain is a process from innovative conception to industrialization; second, innovation chain is a process in which multiple subjects are required to interact to realize innovation. As for models, some scholars have proposed a linear model that starts from basic research and ends in industrial application, as well as a cycle model that is composed of scientific knowledge, technological research and development, product development, market application and other links.

Whatever it is in the shape of a corridor, in mathematics thought is a line, this paper makes the corridor as a unique innovation system, as shown in figure 1, so with the innovation chain perspective to explore the route 128 and Guang-Shen corridor the construction mechanism of the corridor.

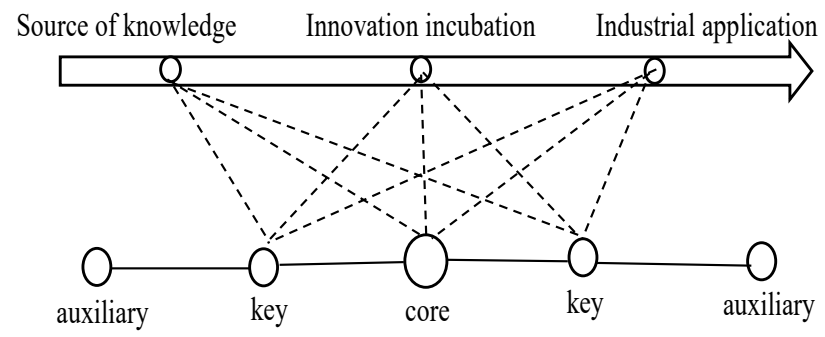

Fig. 1. Matching diagram of innovation (chain) and innovation corridor (ribbon) structure.

\section{Analysis on the construction mechanism of the innovation corridor of 128 highway}

Highway 128 innovation corridor was built in 1951 in Boston, Massachusetts half ring highway, the road on both sides there are thousands of technology-oriented enterprises and research institutions in linear distribution of highway is about $16 \mathrm{~km}$ from downtown Boston, near including MIT and Harvard University, 65 universities, has created the world famous "miracle" in Massachusetts, was also known as "America's technology road" around the world. The Route 128 Innovation Corridor has experienced a boom in the 1960s and 1970s and a bust in the 1980s.In recent decades, with the development of aerospace, precision medicine, new materials, life and health and other fields, it rises again and becomes a world-famous innovation centre again. 


\subsection{Universities, as the source of knowledge, promote the development of regional innovation and entrepreneurship}

The success of Route 128 Innovation Corridor lies in the intellectual power behind it. Route 128 brings together 65 higher education institutions, including Harvard University and the Massachusetts Institute of Technology, to provide Boston's high-tech industrial district with a large number of senior scientists, engineers and technicians. Colleges and universities as the intellectual backing plays an important role in the study of innovation, widely participate in the innovation research, the patent results output unceasingly, high-tech industrial zone along the highway 128 , with $70 \%$ of the enterprise is founded by the Massachusetts institute of technology graduates, so for 128 highway region at the Massachusetts institute of technology have the biggest influence of development of science and technology. In order to promote the rapid transfer and transformation of scientific and technological achievements and attract high-tech enterprises to settle down, Highway 128 has laid out many industrial parks around universities, which greatly strengthens the exchange and cooperation between enterprises and universities, speeds up the transfer and transformation efficiency of intellectual property rights, and is conducive to enterprises' rapid access to scientific and technological achievements of universities. Universities are also supported to set up platforms for the transfer of scientific and technological achievements, such as technology transfer services and technology transfer centres. Colleges and universities are encouraged to promote the existing scientific and technological achievements and to cultivate professional talents in a targeted way. Therefore, Highway 128 gathers many industrial leaders [10], laying a solid foundation for the innovative development of this region.

\subsection{Diversified innovation incubation measures promote regional innovation development}

The innovation incubation in Highway 128 region is mainly manifested in the following three points: First, the industry-university-research cooperation network. Regional innovation and development cannot be separated from the highway 128 model combining production, education and research. Enterprises, research institutions should not be three independent individuals, otherwise it is difficult to form a whole-process innovation industrial chain from basic research to industrialization of achievements. Regional Collaborative Innovation Centre has extensive contact with academia and industry, and encourages R\&D personnel of enterprises, universities and research institutes to participate in the technical cooperation research and development of Collaborative Innovation Centre, and also encourages scientific and technological personnel to have the courage to establish technologybased enterprises.

Second, active venture capital. Boston's financial services industry is very developed, and its venture capital investment ranks second in the United States. Such active venture capital not only promotes the development of local innovation, but also promotes the development of a large number of start-up companies. In addition, there are many venture capital firms that provide seed money for high-tech enterprises; local banks have also taken measures to promote active venture capital by establishing specialized venture capital companies and some semi-official venture capital companies established by the government. All these measures have provided strong and favourable financing conditions for enterprises near Highway 128. Defence investment is also playing an important role in the development of Route 128, and venture capital is also contributing to the development of advanced technologies.

\subsection{Coordinated development of regional integration}

The Route 128 district has established an agency to provide coordination and information services, and the Massachusetts Department of Economic Development has established an Office of Business Development, staffed by experienced professionals who focus on providing a variety of unpaid information services to help businesses in the Route 128 region grow. For example, it answers questions about tax policies of 128 regions, conditions for enterprises to settle in, corresponding encouragement measures, contact information of relevant departments, and legal affairs, so as to help enterprises find solutions to the problems quickly. The Boston City Authority has also organized a quarterly cocktail reception, which will invite governors, mayors, ministers, community and entrepreneurs to exchange information, discuss and discuss the future. The local government has issued a policy that scientific and technological innovation enterprises identified as innovative research or new product development can enjoy a $3 \%$ tax reduction, as well as exemption from sales tax on the purchase of scientific research supplies and office supplies. Most enterprises in the Route 128 area can obtain tax reduction [11].

Therefore, as shown in Figure 2 (a), the brilliance and successful rise of Highway 128 is mainly due to the knowledge source function and innovation incubation function provided by Boston as the core node. The whole scientific innovation chain is complete, and the efficiency of structure and function is maximized by using spatial layout. However, it is well known that in the 1970s, due to the Great Depression of the United States economy, the decrease of military orders from the relevant government, a large number of companies went bankrupt, and the unemployment rate also began to soar, which had a serious negative impact on the economy of the Boston area. Since then, the Route 128 area has been in an economic crisis. In the early 2000s, however, the Route 128 area adjusted its economic structure, focused on Boston's solid industrial base and talent strengths, and developed high-tech industries. The innovation and entrepreneurship atmosphere began to flourish again, 
and Route 128 began to prosper again. Thus, as shown in Figure 2 (b), the decline in the middle period of Highway 128 can be attributed to the weakening of the function of the core node. In the late 1970s, no new node replaced Boston, resulting in the deterioration of the whole scientific innovation chain with no core and no peak. At the beginning of the 21st century, Boston served as the core node to incubate innovation, and the surrounding cities played a supporting role in bringing Route 128 back to its glory.

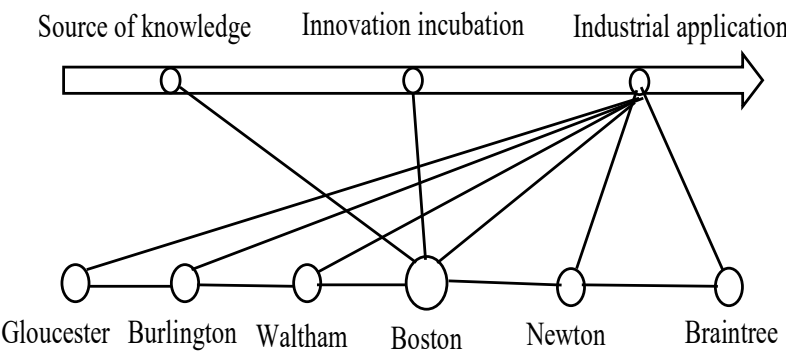

(a) Matching diagram of 128 highway innovation corridor and innovation chain - Initial

Source of knowledge Innovation incubation Industrial application

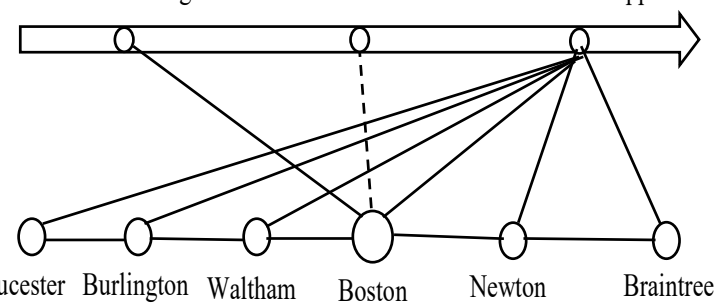

(b) Matching diagram of 128 highway innovation corridor and innovation chain -- Deterioration

Fig 2. Matching diagram of 128 highway innovation corridor and innovation chain

\section{Analysis on the construction mechanism of Guang-Shen science and technology innovation corridor}

Guang-Shen science and technology innovation are relying on the Guang-Shen highway, length of about 180 $\mathrm{km}$, and around the city function orientation is very clear, is a new engine of a large bay area of Guangdong. Guangzhou-Shenzhen Science and Technology Innovation Corridor is dumbbell shaped, among which Guangzhou has a strong science and innovation force, Shenzhen has a high degree of marketization, Dongguan has developed manufacturing industry and perfect supporting facilities, and is the gathering place of Guangzhou and Shenzhen. Therefore, GuangzhouShenzhen Science and Technology Corridor is a corridor formed after the day, which is formed on the basis of industrial economy and technology. Guang-Shen Science and Technology Innovation Corridor adopts the development direction of "one corridor linkage, ten cores drive and multiple points support". According to the report of the 12th Party Congress of Guangdong
Province, Guangdong should learn from the experience of the US Highway 128 Science and Technology Corridor, and the construction of Guangzhou-Shenzhen Science and Technology Innovation Corridor should seize all kinds of excellent innovation resources along the corridor, integrate the resources, radiate and drive the development of surrounding areas, and promote closer cooperation of regional economy.

\subsection{The source of knowledge lays a foundation for the development of regional scientific and technological innovation}

Guang-Shen Science and Technology Innovation Corridor has obvious common characteristics with Silicon Valley and Boston in the United States. Firstly, they are both close to the world-famous Greater Bay Area, with strong industrial support and strong economic foundation. Secondly, the agglomeration of innovation elements such as university research institutions, and the surrounding areas include a number of research and development institutions, new universities, venture capital funds, etc.; in addition, these areas have complete infrastructure and beautiful ecological environment, can attract high-tech talents to land. Guangzhou has 79 institutions of higher learning, 7 state key laboratories and 233 provincial and ministerial key laboratories, among which more than $70 \%$ of the scientific and technological personnel and $95 \%$ of the doctoral students from Guangdong Province are from Guangdong Province. Guangzhou is known as the "Innovation Brain". Shenzhen was once rated as "the pearl on the innovation crown" by the British Economist, and has a number of world-class innovative technology enterprises such as Huawei, ZTE, DJI, BYD [12].

\subsection{Diversified innovation incubation measures promote regional innovation development}

The innovation incubation of Guangzhou-Shenzhen Science and Technology Innovation Corridor is mainly manifested in three aspects. First, give full play to the role of enterprises as the main body of innovation. A combination of measures should be taken to promote enterprises to improve their independent innovation ability, promote enterprises to increase their investment in research and development, support enterprises to jointly set up technology research and development institutions with universities and research institutes, improve the ability to tackle key technologies and core technologies, develop and expand high-tech enterprises, and lead the rapid development of modern industry with innovation. Encouraging enterprises to carry out major science and technology projects and facilitating the active flow of innovation factors to enterprises; increase the number of first-class innovative enterprises, develop and strengthen the development of small and mediumsized innovative enterprises, to form an innovative enterprise cluster with independent intellectual property rights, with independent brands and strong core 
competitiveness; in order to own the independent intellectual property rights, local support to establish a number of overseas production bases and research and development centres, master the key core technology, improve the international standards of enterprises, improve the influence of international product pricing.

Second, the construction of industrial incubation system plays a driving role. The corridor launched "the gen space - accelerator - professional incubator park" as the carrier of the whole chain industry hatching breeding system model, at the same time, taking advantage of the colleges and universities and research institutes focus on resources, lead to all kinds of industrial park, the leading enterprises in construction technology business incubator platform, form the whole cycle cover science and technology enterprise development way. Further implement the incubation and growth plan of science and technology business incubators, and encourage social and private capital to actively invest in incubator construction. The government provides technical skills, science and technology finance, entrepreneurship guidance, inspection and testing services, etc., and guides the incubation institutions to establish a sound ecological chain system, construct professional incubation mode, establish a multi-level service team, improve the success rate of incubated enterprises, and promote the development of regional industries.

\subsection{Coordinated development of regional integration}

Innovation cluster refers to the technology and economic network composed of universities, research institutions, enterprises, venture capital companies, intermediary service organizations, etc., which has the characteristics of agglomeration economy and knowledge spillover. They form strategic alliances or carry out various cooperation through value chain and knowledge chain. Due to the high intensity of R\&D investment, innovation cluster has become an important subject of knowledge transfer and knowledge dissemination, forming an efficient innovation network with multi-subject participation and exerting influence and promoting effect on economy and society. The concrete manifestation of regional integration is: First, promote the policy interaction in the corridor. Focusing on the study of industrial co-construction, opening and sharing of scientific and technological resources within the region and the flow of innovative talents among regions, coordinating and coordinating major science and technology, talents and industrial policies in the corridor to ensure the free flow of talents, capital, technology, information and other innovative elements. Second, unimpeded talent flow channels. Promote the flexible two-way flow of talents between enterprises, universities and research institutions. In addition, by providing highquality educational resources, medical resources and living environment, the supply of urban public services can be improved, which helps to enhance the stickiness of talents in different places and solve the worries of talents. Thirdly, the Guang-Shen Science and
Technology Innovation Corridor breaks down the administrative barriers that hinder technology and innovation, concentrates the innovation resources of the three places, and forms an innovation economic belt with functions running through, industrial linkage and spatial link age. Foreign agglomeration high-tech innovation resources around the world, the innovation of high-tech talent, high-quality scientific research and high-tech innovation enterprises, finally built the global science and technology innovation centre, the national system reform leading demonstration zone, and carrying a large bay area of Guangdong science and technology innovation centre, powerful to promote the implementation of the strategy of developing national innovation drive. Fourth, government guidance and support. The government plays a pivotal role in the construction of the science and innovation corridor, and the government's targeted support is helpful to solve the dilemma of science and technology innovation.

Therefore, the rapid development of GuangzhouShenzhen Science and Technology Innovation Corridor cannot be separated from its clear functional status. As shown in Figure 3, Guangzhou gives full play to the function of knowledge source and takes advantage of the aggregation of universities and research institutions to establish a national innovation centre and an international science and technology innovation hub. Dongguan plays an auxiliary role, establishes a solid foundation between Guangzhou and Shenzhen, takes advantage of manufacturing clusters and industrial parks to build a world-class advanced manufacturing base, so as to support the rapid development of the entire Guangzhou-Shenzhen Science and Technology Innovation Corridor. Shenzhen will give full play to its role as an incubator of innovation, speed up the establishment of an international centre for scientific, technological and industrial innovation, and build an innovative pilot zone with global competitiveness by taking advantage of the concentration of high-tech enterprises and their market-orientation. Among them, we believe that innovation incubation in Shenzhen plays a core function, turning knowledge into productivity, and promoting the rapid development of the whole science and technology innovation chain.

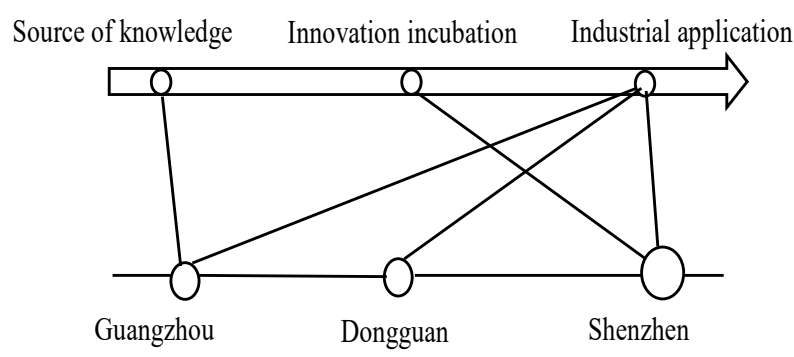

Fig. 3 Matching diagram of Guang-Shen technology innovation corridor and innovation chain

\section{Discussion}

Highway 128 , is a common play a role of government, enterprises and universities an innovation cases, work together to form a ecological chain of innovation, under 
the ecological chain support each other, interaction, mutual influence, and makes the area is full of creativity, meanwhile combined with the national innovation system, makes the whole route 128 regional common prosperity development innovation. Shenzhen science and technology innovation corridor, Guangzhou and Shenzhen gathered a number of first-class universities, research and development centre, corporate research park, industrial park, national laboratories, industrial manufacturing base, makes the information exchange, technical services, education and training, financial support and other innovative elements flow between entrepreneurs, can speed up the transformation of scientific and technological achievements transfer, effectively reduce the business risk. Based on the above case analysis, we sorted out the basic situation of the case and the functions of each node, as shown in Table 1 and Table 2.

Table 1 Summarize the basic situation

\begin{tabular}{|c|c|c|}
\hline Elements & $\begin{array}{l}\text { Innovation corridor } \\
\text { of Highway } 128\end{array}$ & $\begin{array}{l}\text { Guang-Shen Science } \\
\text { and Innovation } \\
\text { Corridor }\end{array}$ \\
\hline $\begin{array}{c}\text { Geographical } \\
\text { space }\end{array}$ & $\begin{array}{c}\text { A semicircle } \\
\text { stretching from } \\
\text { Gloucester to } \\
\text { Braintree, with } \\
\text { Boston as the centre, } \\
\text { linking cities }\end{array}$ & $\begin{array}{c}\text { Guangzhou, } \\
\text { Dongguan and } \\
\text { Shenzhen will be } \\
\text { connected into an } \\
\text { innovative economic } \\
\text { belt }\end{array}$ \\
\hline $\begin{array}{c}\text { Source of } \\
\text { knowledge }\end{array}$ & $\begin{array}{c}\text { Harvard University, } \\
\text { MIT, Boston } \\
\text { University, } \\
\text { Northeastern } \\
\text { University, etc. }\end{array}$ & $\begin{array}{c}\text { South China } \\
\text { University of } \\
\text { Technology, Jinan } \\
\text { University, South } \\
\text { China Normal } \\
\text { University, etc. }\end{array}$ \\
\hline $\begin{array}{l}\text { Innovation } \\
\text { incubation }\end{array}$ & $\begin{array}{l}\text { Industry-University- } \\
\text { Research } \\
\text { cooperation network; } \\
\text { active venture capital }\end{array}$ & $\begin{array}{c}\text { Strengthen the } \\
\text { construction of } \\
\text { industrial incubation } \\
\text { system }\end{array}$ \\
\hline $\begin{array}{l}\text { Regional } \\
\text { integration }\end{array}$ & $\begin{array}{l}\text { Complementary } \\
\text { industrial } \\
\text { advantages; the } \\
\text { combination of } \\
\text { government and } \\
\text { market forces }\end{array}$ & $\begin{array}{c}\text { Break down } \\
\text { administrative } \\
\text { barriers internally and } \\
\text { gather global } \\
\text { innovation elements } \\
\text { externally }\end{array}$ \\
\hline
\end{tabular}

Table 2 Function analysis of each node of Highway 128 Innovation Corridor and Guang-Shen Science and Technology Innovation Corridor

\begin{tabular}{|l|l|}
\hline $\begin{array}{l}\text { Innovation corridor of } \\
\text { Highway 128 }\end{array}$ & $\begin{array}{l}\text { Guang-Shen Science and } \\
\text { Innovation Corridor }\end{array}$ \\
\hline $\begin{array}{l}\text { Boston-Source of } \\
\text { knowledge }\end{array}$ & $\begin{array}{l}\text { Guangzhou-Source of } \\
\text { knowledge }\end{array}$ \\
\hline $\begin{array}{l}\text { Boston-Innovation } \\
\text { incubation(Core Node - Core } \\
\text { functionality) }\end{array}$ & $\begin{array}{l}\text { Shenzhen-Innovation } \\
\text { incubation(Core Node - Core } \\
\text { functionality) }\end{array}$ \\
\hline $\begin{array}{l}\text { Braintree, Gloucester- } \\
\text { Auxiliary function }\end{array}$ & $\begin{array}{l}\text { Dongguan -- Promote } \\
\text { integrated development }\end{array}$ \\
\hline
\end{tabular}

Through the case analysis of Highway 128 Innovation Corridor and Guang-Shen Science and Technology Innovation Corridor, we can summarize the construction mechanism of the science and technology innovation corridor.

This paper describes the chain of the science and innovation corridor as from the source of knowledge to innovation incubation and then to industrial application. Meanwhile, the whole corridor has its own unique geographical spatial distribution, and finally forms the regional integration and coordinated development. First of all, the knowledge source has a lot of channels, universities, research institutions, research institutes, platform are corridor knowledge source, production, collaborative innovation is the enterprises, universities, research institutes, such as the innovation main body involved in each other, play to their respective advantages, knowledge production, scientific research and economic development organically, through resource sharing between each other and complementary advantages, realize the main body of innovation and win-win. In the science and innovation corridor, through the division of labor of different subjects in the upper, middle and lower reaches, a network organization structure is formed to realize the virtuous cycle development of resources and elements in the corridor.

Secondly, the transformation of scientific and technological achievements is the key link to transform science and technology into realistic productive forces. Scientific and technological knowledge is the foundation of enterprise innovation, it is only a potential capital, and cannot create real productivity value by itself. Therefore, in order to promote the development of the science and innovation corridor, how to maximize this potential advantage into the reality of competitive advantage is the key. Therefore, diversified innovation incubation system is needed to turn knowledge source into productivity. Multiple innovation entities work together in the same direction to form synergy in scientific and technological innovation and provide driving force for the development of the science and innovation corridor.

Finally, the science and innovation corridor is a characteristic collaborative innovation zone across the administrative boundary. The key to its construction is to break the barrier of the city boundary and strengthen the flow of elements between the cities along the corridor. The full flow of factors is an important basis for regional integration, including talent exchange, capital docking, project cooperation and so on. In order to promote the steady and sustainable development of the science and innovation corridor, it is necessary to strengthen the interaction between cities along the corridor, build a coordinated urban network, and form a regional integrated development. The special organizational structure of the science and innovation corridor is also integrated in the coordination of various subsystems.

\section{Conclusion}

First, the construction mechanism of the science and innovation corridor. This paper describes the chain of 
the science and innovation corridor as from the source of knowledge to innovation incubation and then to industrial application. This is very similar to the innovation chain model. Corridor contains a variety of subjects, many links, but all the subjects are not equal, at least one node plays a leading role, gathering and leading role. Each science and innovation corridor should have a core node playing its core function, that is, "high mountains rise from high peaks, high peaks rise from high peaks to high plateaus". If there is no core node or if the core node is weak, we conclude that the corridor will not succeed and will exhibit a state of deterioration. Under the multi-subject governance structure, each governing body plays different functional utility with its different function orientation. The elements in the corridor should gather to the core nodes actively. As an organizational form, the corridor should not just stay in the static balance between "utilization" and "exploration" to deal with the most fundamental problems in the process of innovation challenges, but should constantly coordinate the dynamic balance within the region, so that the whole corridor can achieve sound development.

Second, the core nodes of the science and innovation corridor are nodes corresponding to the innovation incubation function. Corridor need resources agglomeration. In our case study, the core node in Boston and Shenzhen. They are both big cities with capabilities, resources and environment. Only as the core node, they can have the ability of the agglomeration and diffusion, playing the core capabilities, to play a leading and support for the whole of the coordinated development of corridor.

Current research "chain" concept has been widely applied to various fields, this paper studies from the Angle of innovation chain corridor characteristics and its construction mechanism, through the study of corridor, in turn, we will find the "breaking point" of the innovation chain is mainly produced in knowledge resources agglomeration to achievements transformation stage, the innovation of the multivariate hatch is the key to the success of corridor construction, innovation chain is the link between weak point, improve the links of the core of the innovation chain is the key to optimize the link between the problem. Only by integrating various resource elements and getting through all links of the innovation chain at the same time can the whole chain give full play to its effect.

\section{Acknowledgment:}

Zhejiang Provincial Soft Science Research Project " Research on the G60 Science and Innovation Corridor (Zhejiang Section) Construction of Yangtze River Delta Region Collaborative Innovation Highland " (2020C25038)

\section{References}

1. Kang Jian, $\mathrm{Hu}$ Zuguang. Research on the relationship between multiple networks in innovation chain, entrepreneurial capability and entrepreneurial performance [J].Science and Technology Management Research,2017,37(02): 716.

2. Lin Lei, Wu Jiaxi, Wang Ping. Symbiotic Coupling of Science and Technology Intermediary Service Chain and Innovation Chain: Theoretical Connotations and Policy Implications [J].Technology Economics,2014,33(06): 7-12+25.

3. Zhang Gui, Wen Ke. Collaborative innovation, regional integration and innovation performance: A comparative study of three regional data in China $[\mathrm{J}]$.Science and Technology Progress and Countermeasures,2017,34(05): 35-44.

4. Zhang Fanyong, Du Yueping. The Concept, Connotation and Policy Implications of Innovation Chain [J].Journal of Business Economics,2020(22): 130-132.

5. Judith J M. An Empirical Study of Factors Influencing Innovation Organizations in Industrial Sales [J]. Journal of the Academy of Marketing Science, 1992,20(03): 205-215.

6. JIANG Xin-juan, WU Fu-xiang, CONG Hai-bin. Heterogeneous R\&D, knowledge spillover and firm innovation output: An empirical analysis from the perspective of innovation chain [J].Science and Technology Progress and Countermeasures,2020,37(24): 80-89.

7. Wu Xiaobo, Wu Dong. On the System Evolution of Innovation Chain and Its Policy Implications [J].Research on Dialectics of Nature,2008,24(12).

8. Zhou Xueliang, Zhang Jihai, Han Zhihong. Research on the Collaborative Innovation Development Mode of Military and Civilian Science and Technology in Science Park Driven by Innovation Chain [J].Science and Technology Progress and Countermeasures, 2019,1-8.

9. Ding Can, Zhu Guangcai, Li Jing. An Analysis of Civil-Military Integration Collaborative Innovation Based on Innovation Chain [J].Journal of Xihua University,2018,37(05): 49-54.

10. Li Xiaofeng. Theoretical Research on Improving the Level of Innovation Ecosystem with the Integration of "Four Chains" [J].Science Research Management,2018,39(09): 113-120.

11. Wang Yudong, Zhang Bo, Wu Chuan, et al. Research on the Synergy Degree Measurement of Innovation Chain and Capital Chain of High-tech Industry -- Based on the Synergy Degree Model of Composite System [J].Science and Technology Progress and Countermeasures,2019,36(23): 63-68.

12. Foxon $\mathrm{T} J$, et al. Drivers, barriers and systems failures of renewable energy technologies [J]. Energy Policy,2004,33(10): 1073-1079. 